\title{
Undifferentiated carcinoma of esophagus
}

INSERM

\section{Source}

INSERM. (1999). Orphanet: an online rare disease and orphan drug data base.

Undifferentiated carcinoma of esophagus. ORPHA:418951

A rare, agg ressive, malignant, epithelial carcinoma of the esophagus characterized, macroscopically, by an exophytic mass with central ulceration located on the esophagus and, histologically, by a sheet-like growth of neoplastic cells without significant glandular, squamous or neuroendocrine differentiation. Patients may present with progressive dysphagia, long-standing history of gastroesophageal reflux, weight loss, anemia, abdominal or chest pain/pressure, dyspnea, and/or hematemesis. Presence or history of Barrett esophagus is frequently associated. 